\title{
A Comparative Study between Pseudo-static and Dynamic Analyses on Rock Wedge Stability of an Arch Dam
}

\author{
Hasan Mostafaei ${ }^{\mathrm{a}}$, Morteza Sohrabi Gilani ${ }^{\mathrm{b}}$, Mohsen Ghaemian ${ }^{\mathrm{c}}$ \\ ${ }^{a}$ PhD Candidate, Faculty of Civil Engineering, Isfahan University of Technology, Isfahan, Iran . \\ ${ }^{b}$ Assistant Professor, Department of Civil Engineering, University of Guilan, Rasht, Iran. \\ ${ }^{c}$ Professor, Faculty of Civil Engineering, Sharif University of Technology, Tehran, Iran. \\ Received 22 November 2017; Accepted 15 January 2018
}

\begin{abstract}
In this study, the abutment stability of arch dams for two cases of pseudo-static and dynamic methods were compared based on limit state equilibrium method. For the pseudo-static approach, unit accelerations were applied to the model in three directions for calculating thrust forces. For dynamic analysis, three components of ground acceleration time histories of Kobe earthquake, 1979 were applied to the finite element model of dam-foundation-reservoir, and the thrust forces were obtained. The effect of reduction factors in pseudo-static analysis is investigated in order to obtain the reduction factor that corresponds to wedge movement in dynamic analysis. For this purpose, the reduction factors have been increased from 0.5 to 1 . The obtained results indicate that pseudo-static results are more conservative than the dynamic analysis method for small reduction factors and the reduction factor plays a key role on the abutment stability analysis.
\end{abstract}

Keywords: Abutment Stability; Dynamic Analysis; Pseudo-Static Analysis; Safety Factor Of Wedge; Reduction Factor; Londe Method.

\section{Introduction}

Generally, concrete arch dams are large structures that should be investigated for seismic loadings. An arch dam potentially may fail because of excessive contraction joint opening combined with cantilever tensile cracking, sliding along the gently sloped dam- foundation interface and in certain cases movement of the abutment rock wedges formed by foundation joints and discontinuities. Abutments of concrete arch dams are usually crossed by several joints, faults, cracks and fractures, which may create some rock wedges. One of the most important failure modes especially to the stability of arch dams involve abutment rock wedges that are kinematically capable of movement [1]. The abutment stability studies are the most important aspects in the stability of arch dams. For this purpose, it is completely necessary to develop an appropriate and reasonably conservative approach in order to evaluate the stability and safety of the dam.

In 1973, Londe presented limit equilibrium approach for the stability analysis of dam abutments. In this approach, the wedge failure is likely to happen only in case of its movement on one or two of its supporting surfaces in the opposite direction of the wedge corner [2,3]. This method has been the topic of many studies in these years and broadly used by dam designers.

Boyer and Ferguson investigated the sliding stability of rock foundations for dams [4]. In their study, the important parameters was determined in evaluating the wedge stability. Noble and Nuss evaluated the effect of wedge stability of

* Corresponding author: m.sohrabi@guilan.ac.ir

\footnotetext{
doi http://dx.doi.org/10.28991/cej-030977

$>$ This is an open access article under the CC-BY license (https://creativecommons.org/licenses/by/4.0/).

(C) Authors retain all copyrights.
} 
abutment on nonlinear seismic behavior of Morrow Point dam. They indicated that when the wedge is not restricted or tied to the dam or foundation, the contraction joint openings are more severe [5]. At the same time, Zuyu Chen has investigated the response of rock wedges and proposed a generalized limit equilibrium analysis method for tetrahedral rock wedge stability studies [6].

She [7] studied the effect of the fault on deformation and stability of the abutment. The results indicated that when the reservoir is impounded, the abutment may slide alone the intersection of fault and bedding plane. Yu et al. [8] investigated the stabilities of the abutments of Houhe gravity-arch dam using block theory and elasto-plastic finite element analyses.

Sohrabi et al. investigated the stability of dam abutments including seismic loading. Time histories of safety factors as well as wedge displacement were presented [9]. Zenz et al. investigated the interaction of wedge, the dam and the abutment in concrete arch dams. They found that the- simplified- rigid body method used to carry out the abutment stability analysis under dynamic earthquake loading leads to a conservative factor of system safety [10]. Takalloozadeh and Ghaemian conducted an analytical study on Shape optimization of concrete arch dams considering an abutment stability constraint. The result showed that abutment stability plays a key role in the optimum shape of arch dams [11]. Mirzabozorg et al. investigated the static and seismic stability of rock wedges of dams. The results indicated that the traditional method overestimated the wedge displacement in comparison with the finite element method [12]. Mahmoudi et al. investigated the effect of foundation nonlinearity on the seismic response of an existing arch dam. In their study, the opening/slipping of joints between a potential wedge at the left abutment and remaining foundation originated the nonlinear behavior in foundation. They indicated that the considering foundation nonlinearity has no significant effect on the results in the considered case due to special design of the body shape [13]. Mostafaei et al. conducted an analytical study on abutment stability due to seismic loading to obtain the probable wedge displacements. They found that the uplift pressure plays a key role in the abutment stability analysis and it is necessary to control the uplift pressure and seepage in arch dam foundations [14, 15].

In this study, Londe method is used for investigating the stability of abutment of arch dams. Moreover, abutment stability of Luzzone dam due to static and seismic loading is investigated. For different reduction factors, the safety factor of the wedge for two cases of pseudo-static and dynamic methods are compared. The obtained results showed that pseudo-static results are more conservative than the dynamic analysis for small reduction factors. The safety factor in the pseudo static method should not be considered less than 1.1 to guarantee the wedge stability. The obtained results indicate that the reduction factor of 0.88 corresponds the wedge stability in dynamic approach.

\section{Wedge Stability Evaluation}

\subsection{Load}

For investigating the stability of abutment of an arch dam, it is essential to determine the applied loads. The forces that affect the abutment stability are: weight of the wedge, uplift pressure, seismic loadings and thrust forces.

The resultant of the applied forces can be calculated as:

$$
\begin{aligned}
& F_{W}^{W}=\left[\begin{array}{c}
0 \\
0 \\
-m^{W} \\
\times g
\end{array}\right] \\
& F_{U p}^{W}=\left[\begin{array}{l}
U_{x} \\
U_{y} \\
U_{z}
\end{array}\right]=\beta_{1}\left[\begin{array}{l}
U_{1-x} \\
U_{1-y} \\
U_{1-z}
\end{array}\right]+\beta_{2}\left[\begin{array}{l}
U_{2-x} \\
U_{2-y} \\
U_{2-z}
\end{array}\right]+\beta_{3}\left[\begin{array}{l}
U_{3-x} \\
U_{3-y} \\
U_{3-z}
\end{array}\right] \\
& F_{E Q}^{W}=-m^{W} \times\left[\begin{array}{l}
\ddot{u}_{g-x} \\
\ddot{u} g-y \\
\ddot{u}_{g-z}
\end{array}\right] \\
& F_{T H}^{D}=\left[\begin{array}{c}
F_{T H-x}^{D} \\
F_{T H-y}^{D} \\
F_{T H-z}^{D}
\end{array}\right]
\end{aligned}
$$

Where $m^{w}$ and $U_{i}$ are the mass of the wedge and total uplift force on i-th plane of the wedge, respectively. Also $\beta_{i}$ is the coefficient of total uplift force on i-th plane of the wedge in load combinations.

For dynamic analysis $\ddot{u}_{g-x}, \ddot{u}_{g-y}, \ddot{u}_{g-z}$ and $F_{T H}^{D}$ are three components of ground acceleration time histories and the thrust force due to static and seismic loadings, respectively. For the purpose of analysis, it is required to develop a 
three dimensional finite element model of dam-foundation-reservoir to calculate the thrust forces. All three components of earthquake ground motions can be applied to the finite element model, simultaneously.

For pseudo-static analysis the ground accelerations may be written in terms of the horizontal and vertical peak ground accelerations (i.e., $a_{h}$ and $a_{v}$ ) and the corresponding pseudo-static coefficients (i.e., $\alpha_{h}$ and $a_{h}$ ). In order to consider the most unfavorable direction of the seismic loads the angle of exciting earthquake force, $\theta$ is applied in all 360 degrees. The applied acceleration on wedge in pseudo-static analysis is represented in vector notation as follow:

$\left[\begin{array}{l}\ddot{u}_{g-x} \\ \ddot{u}_{g-y} \\ \ddot{u}_{g-z}\end{array}\right]=\left[\begin{array}{cc}\cos \theta & 0 \\ \sin \theta & 0 \\ 0 & 1\end{array}\right]\left[\begin{array}{l}\alpha_{h} a_{h} \\ \alpha_{v} a_{v}\end{array}\right]$

In these analyses, the thrust forces, which are applied by the dam to the wedge, include two different load cases, static and pseudo static load. It is worth mentioning that the hydrodynamic pressure is considered in all seismic load combinations.

$F_{T H}^{D}=F_{\text {Static }}^{D}+F_{E Q}^{D}$

Where,

$F_{T H}^{D}=F_{\text {Static }}^{D}+(1 / g)\left[\begin{array}{ccc}F_{E Q-x}^{D} & F_{E Q-y}^{D} & F_{E Q-z}^{D}\end{array}\right]\left[\begin{array}{c}\ddot{u}_{g-x} \\ \ddot{u}_{g-y} \\ \ddot{u}_{g-z}\end{array}\right]$

The total force can be rewritten as follow:

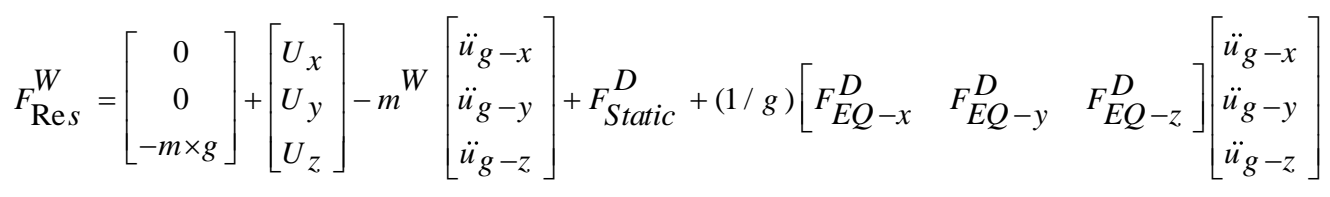

\subsection{Equilibrium Equations and Sliding Modes}

Equilibrium equations can be used to obtain three corresponding reaction forces on the planes, $N_{1}, N_{2}$ and $N_{3}$. It is worth mentioning that the planes are sole compressive and tensile normal forces mean that the planes are opened. When a plane is open, it can be concluded that the considered sliding mode is not appropriate and it will lead to the other different sliding modes excluding this plane.

All sliding modes are described briefly in the following:

If all the plane normal reaction forces are compressive, it means that all planes are in contact. Therefore, the wedge is perfectly stable.

If two of the normal forces on planes are in tension (the third plane reaction is compressive), by ignoring the opened planes and solving the equilibrium equations, the normal and shear forces on the third plane are obtained. The safety factor can be calculated as follow:

$$
S . F .=\frac{N_{3} \tan \phi+C_{3} A_{3}}{V}
$$

If just two of normal forces are compressive, it means that two corresponding planes (i.e. 1 and 2) are still in contact. In such cases by solving the equilibrium equation and ignoring the third plane, the normal forces on the planes as well as the shear force in the direction of planes interface are obtained. The safety factor is calculated as follow:

$S . F .=\frac{N_{1} \tan \phi_{1}+N_{2} \tan \phi_{2}+C_{1} A_{1}+C_{2} A_{2}}{V}$

Where

$N_{i}$ : Normal force on i-th plane

$\phi_{i}$ : Friction angle on i-th plane

$C_{i}$ : Cohesion on i-th plane

$A_{i}$ : Area of i-th plane

$V$ : Shear force 
If all the reactions of planes are in tension and the wedge is detached from all its three supporting planes the other sliding modes should be checked and if the assumption that all planes are in tension has been verified, it means that the wedge is completely unstable.

A computer software called ASAD (Abutment Stability Analysis of Dams) is developed for stability analysis of abutment of arch dams. This software is able to provide some extensive capabilities for dynamic and pseudo-static approaches. Considering static and dynamic analyses, shear resistance parameters of planes and applied loads, possibility of selecting different load combinations and analysis approach beside user friendly area of the software for wedge geometry definition and carrying out the sensitive analysis and its pre and post processing capabilities make this software a complete and powerful package for the abutment stability of arch dams.

\section{Case study}

The Luzzone dam is selected to investigate the abutment stability due to seismic loading. The Luzzone dam is a 225 m high double curved concrete dam that completed in 1963 [16]. Figure 1 shows a view of Luzzone dam.

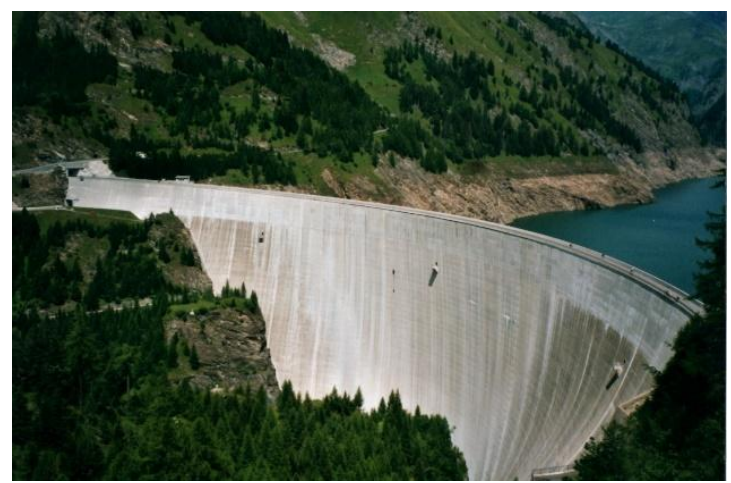

Figure 1. Overall view of Luzzone dam

The concrete of dam body is considered to be linearly elastic with the Young's modulus of 27.0 GPa and Poisson's ratio of 0.18 , and the concrete density is set to $2400 \mathrm{~kg} / \mathrm{m}^{3}$. The elastic modulus, Poisson's ratio and density of foundation rock are considered as $25 \mathrm{GPa}, 0.2$ and $2643 \mathrm{~kg} / \mathrm{m}^{3}$, respectively. The damping ratio of the dam and foundation materials are considered 5\% using the modified Rayleigh damping method [16].

\subsection{Finite Element Model}

A finite element model has been developed to calculate the thrust force applied by the dam to the wedge, due to different load combinations. For this purpose, 332 and 2984 eight nodes brick elements have been used to model dam body and foundation, respectively. Figure 2 shows the dam-foundation finite element model. This model includes 249 and 3797 nodes for dam body and foundation, respectively.

The reservoir is meshed by using 1474 nodes and 1080 eight nodes acoustic elements.

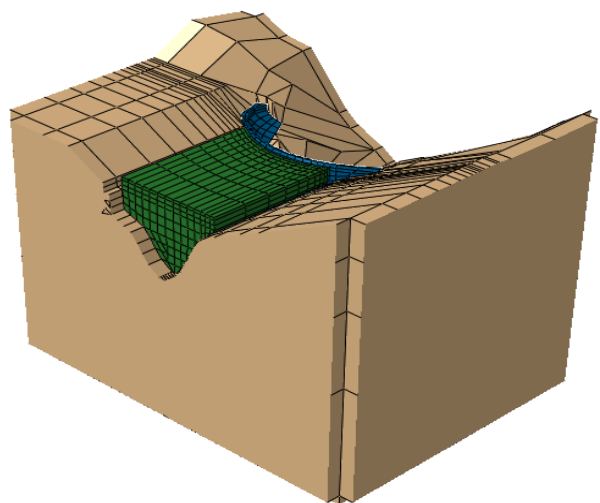

a) Dam-foundation-reservoir finite element model

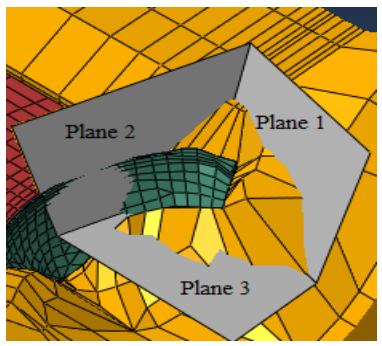

b) Geometry of the wedge

Figure 1. Luzzone dam model 


\subsection{Wedge Definition}

As shown in Figure 1, three joint surfaces and discontinuities that intersect the abutment of the Luzzone dam create a contact wedge, and its stability should be checked for different load combination. The characteristics of this wedge including each plane orientation (i.e., Dip- and Dip-direction angels), areas and shear strength parameters of discontinuities is presented in Table 1 [16].

Table 1. Characteristic of the wedge [16]

\begin{tabular}{ccc}
\hline & Friction degree & 35 \\
Plane 1 & Area & 23300 \\
& Dip angle & 65 \\
& Dip direction & 5 \\
\hline \multirow{2}{*}{ Plane 2 } & Friction degree & 35 \\
& Area & 28650 \\
& Dip angle & 0 \\
& Dip direction & 0 \\
\hline \multirow{2}{*}{ Plane 3 } & Friction degree & 35 \\
& Area & 7200 \\
& Dip angle & 76 \\
& Dip direction & 280 \\
\hline
\end{tabular}

\subsection{Load Combination}

In order to investigate the stability of the wedge, 11 load combinations are considered which are listed in Table 2. The load combinations are defined in a way to study the grout curtain efficiency on wedge stabilities. Zero values of the coefficient of load combination demonstrates that grout curtain works properly while the values equal to 1 , corresponds its failure.

Table 2. Load combinations

\begin{tabular}{ccccc}
\hline Combination & Weight & Uplift & EQ & Thrust Force \\
\hline Combo 1 & 1.0 & 0.0 & 1.0 & 1.0 \\
Combo 2 & 1.0 & 0.1 & 1.0 & 1.0 \\
Combo 3 & 1.0 & 0.2 & 1.0 & 1.0 \\
Combo 4 & 1.0 & 0.3 & 1.0 & 1.0 \\
Combo 5 & 1.0 & 0.4 & 1.0 & 1.0 \\
Combo 6 & 1.0 & 0.5 & 1.0 & 1.0 \\
Combo 7 & 1.0 & 0.6 & 1.0 & 1.0 \\
Combo 8 & 1.0 & 0.7 & 1.0 & 1.0 \\
Combo 9 & 1.0 & 0.8 & 1.0 & 1.0 \\
Combo 10 & 1.0 & 0.9 & 1.0 & 1.0 \\
Combo 11 & 1.0 & 1.0 & 1.0 & 1.0 \\
\hline
\end{tabular}

\section{Result and Discussion}

\subsection{Seismic Analysis}

The ground acceleration time history of Kobe 1979 is considered for seismic analysis. These records are normalized for the PGA from 0.1 to $0.5 \mathrm{~g}$ by $0.05 \mathrm{~g}$ steps. The ground acceleration earthquakes are applied in stream (x-direction), cross-stream (y-direction) and vertically upward (z-direction) directions simultaneously. Thrust forces due to static and seismic loadings are obtained by using the finite element analysis of the prepared model. The time history of safety factors of stability analysis due to seismic loading for the horizontal PGA of $0.35 \mathrm{~g}$ is shown in 
Figure 2. As it is shown, the safety factor of the wedge in the time period between 8 to 13 seconds takes values less than 1 which corresponds to the wedge movement.

\subsection{Pseudo-Static Analysis}

In order to compare the pseudo-static and dynamic stability analyses, the PGA of horizontal and vertical components are used in pseudo-static analysis. As it is mentioned, in order to compute the minimum of the safety factor, the directions of applied horizontal acceleration are applied in 5 degrees intervals.

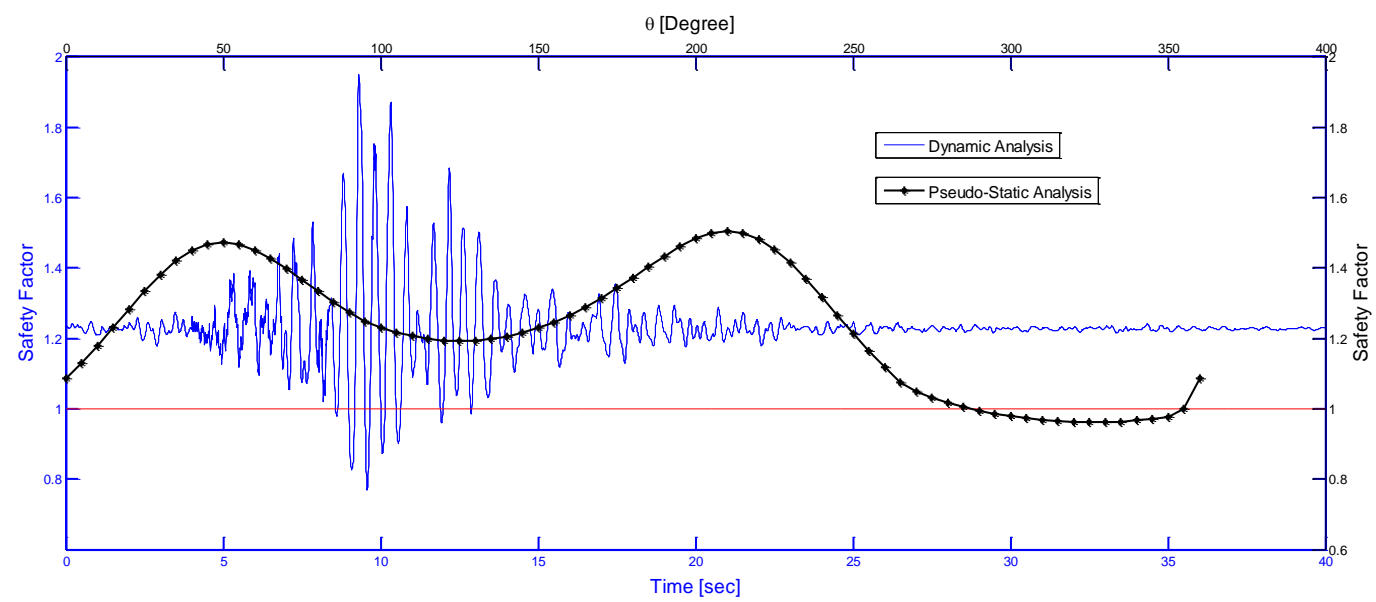

Figure 3. Comparison of safety factor of wedge for dynamic and pseudo-static approach (PGA=0.35 g)

Figure 3 demonstrates that the safety factor varies from $0.96(=325)$ to $1.50(=210)$ which reveals that rotating the applied horizontal acceleration for finding the most unfavorable direction of earthquake loads has a paramount effect on the wedge stability and should be investigated in all analyses. As it is clear, the minimum safety factor in dynamic approach $(\mathrm{SF}=0.77)$ is less than pseudo-static approach.

\subsection{The Effect of Reduction Factor}

In order to investigate the effects of reduction factor on the safety factor of the wedge, the reduction factors have been increased from 0.5 to one by step of 0.05 . The safety factor of wedge for pseudo-static analysis due to different reduction factors is depicted in Figure 4. As it is clear, the reduction factor plays a key role in analysis of abutment stability.

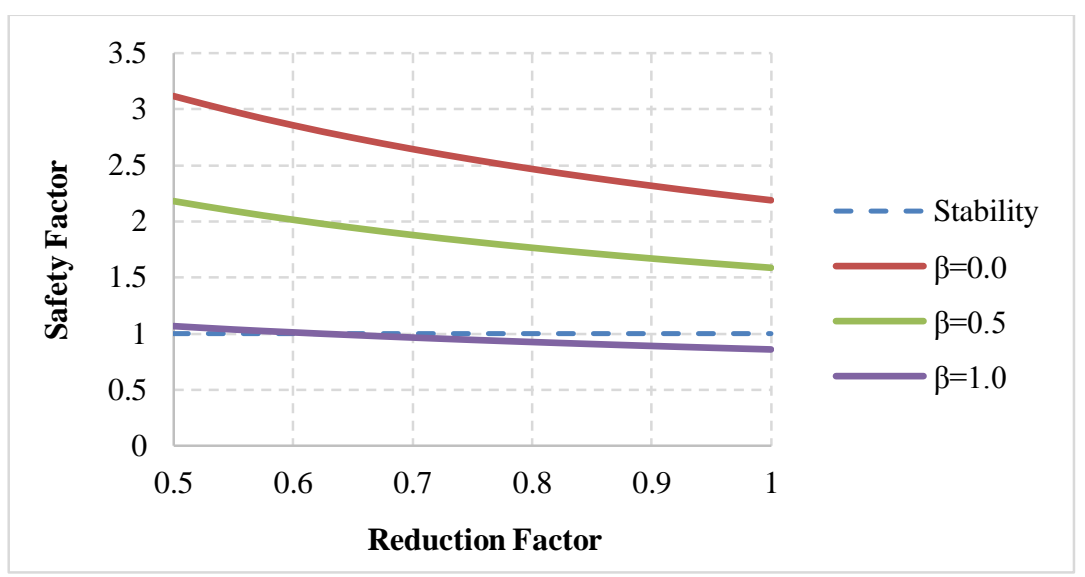

Figure 4. The reduction factor effects on the minimum safety factor of the wedge (PGA=0.35 $\mathrm{g})$

In order to calculate the reduction factor in pseudo static method, which corresponds wedge movement in dynamic approach, the minimum safety factor in both methods are presented in Figure 5 for different reduction factors. For this purpose, the PGA of records has been increased from 0.1 to $0.5 \mathrm{~g}$. It is worth mentioning that 99 number of separate pseudo-static and dynamic analyses has been carried out for each reduction factor. 

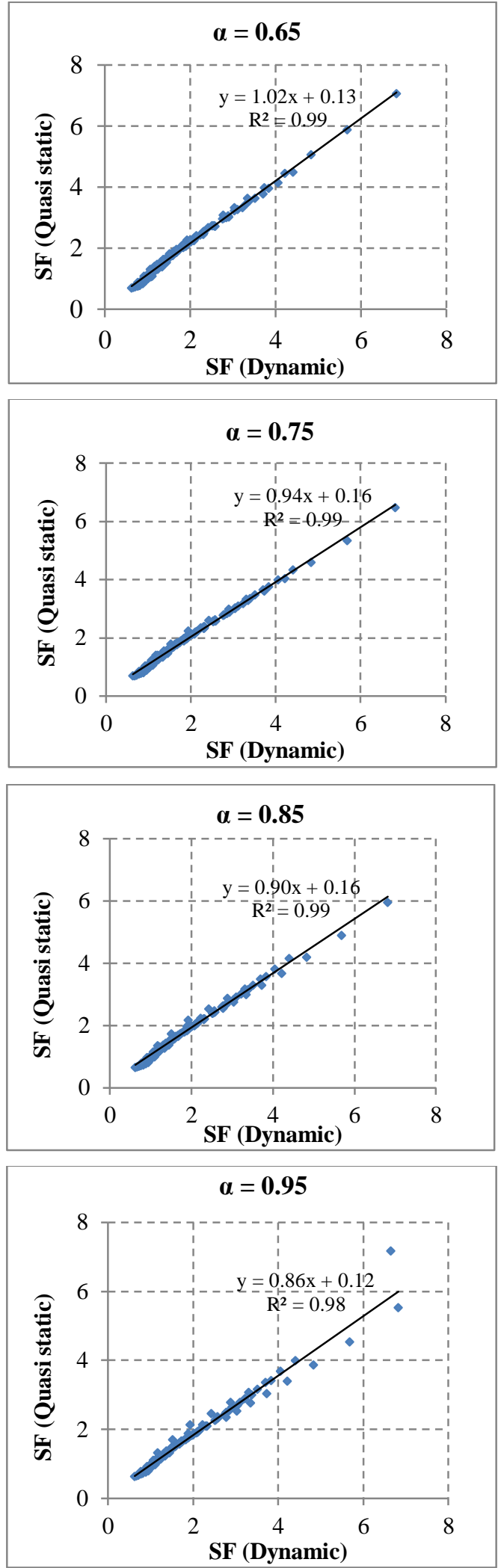
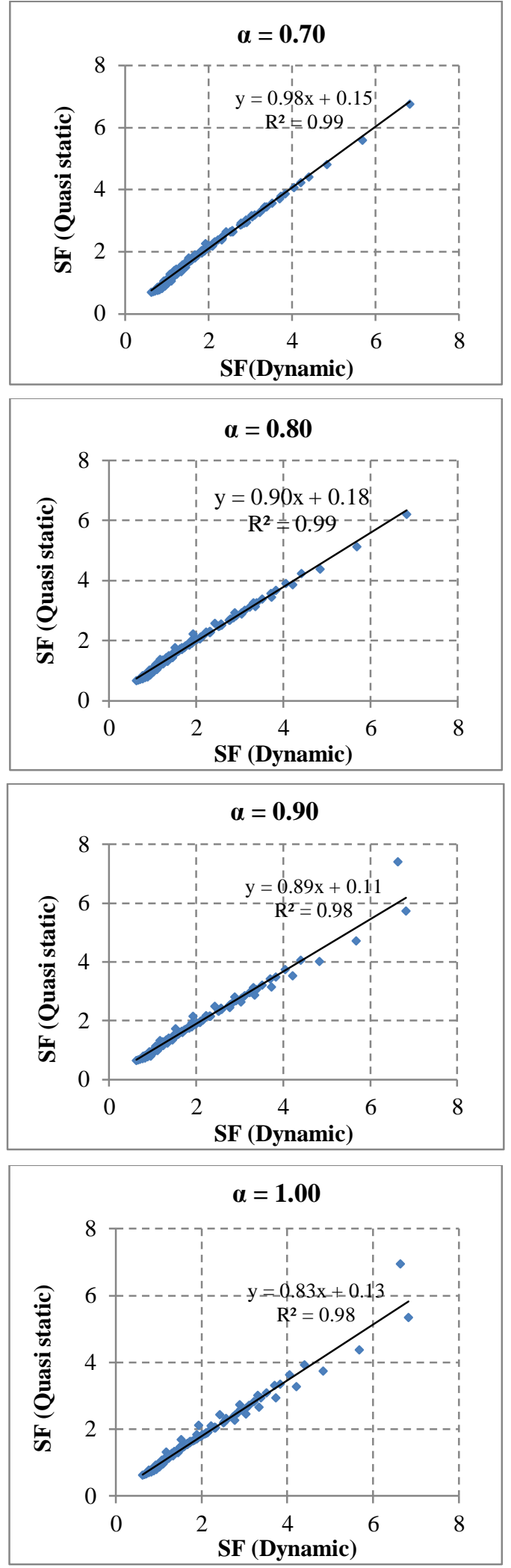

Figure 5. The minimum safety factor in dynamic and pseudo-static analyses for different reduction factors

As it is illustrated in this Figure, the pseudo-static analysis is more conservative than dynamic analysis, which is expected. Safety factor in Pseudo-static analysis corresponds to instability threshold in dynamic analysis for different values of reduction factor are reported in Table 3. 
Table 3. Safety factor in Pseudo-static analysis corresponds to instability threshold in dynamic analysis for different values of reduction factor

\begin{tabular}{cc}
\hline Reduction factor & $\begin{array}{c}\text { Safety factor in Pseudo-static analysis correspond to } \\
\text { instability threshold in dynamic analysis }\end{array}$ \\
\hline 0.65 & 1.15 \\
0.70 & 1.13 \\
0.75 & 1.10 \\
0.80 & 1.08 \\
0.85 & 1.06 \\
0.90 & 1.00 \\
0.95 & 0.98 \\
1.00 & 0.96 \\
\hline
\end{tabular}

The obtained results show that the reduction factor in Pseudo-static analysis, which is equivalent to instability threshold in dynamic analysis, is 0.88 . The safety factor in the pseudo static method should not be considered less than 1.1 to guarantee the wedge stability for reduction factor of 0.65 .

\section{Conclusion}

One of the most significant current discussions in the dam design is the abutment stability analysis of arch dams. For decades, the pseudo-static method due to its simple approach is used by most of dam designers. In the present paper, the effect of reduction factor on the safety factor of wedge is investigated. For this purpose, the pseudo-static and dynamic analyses were compared. The obtained results reveal that in pseudo-static approach, reduction factor and rotation of exiting earthquake force play key roles in the analysis of abutment stability. Finding a correlation between the dynamic and pseudo-static methods is one, the other main issues that is investigated it this study. As it is expected, the pseudo-static method is more conservative. The comparison of the pseudo static and dynamic approaches indicate that the safety factor of 1.14 in pseudo-static approach with $\alpha=0.67$ corresponds to instability threshold in dynamic approach which is in accordance and consistent with design criteria of guidelines which present the minimum of safety factor of 1.1. The approximate value for reduction factor for safety factor in pseudo-static analysis, which is equivalent to instability threshold in dynamic analysis, is 0.88 .

\section{References}

[1] Ghanaat, Y. "Failure modes approach to safety evaluation of dams," in Proceedings of the 13th World Conference on earthquake engineering, 2004.

[2] Londe, P. "Analysis of the stability of rock slopes," Quarterly Journal of Engineering Geology and Hydrogeology, 6 (1973): 93 124.

[3] Londe, P. "The Malpasset dam failure," Engineering Geology, 24 (1987): 295-329.

[4] Boyer, D.D. and Ferguson, K.A. Important factors to consider in evaluating sliding stability of rock foundations for dams. 16th Annual Conference: Association of State Dam Safety Officials (ASDSO), October 10-13, 1999. ST. Louis, US.

[5] Noble, Charles R., and Nuss, Larry K.. Nonlinear seismic analysis of Morrow Point dam. 13th World Conference on Earthquake Engineering Vancouver, Canada, 1-6, August 2004.

[6] Chen, Z. "A generalized solution for tetrahedral rock wedge stability analysis," International Journal of Rock Mechanics and Mining Sciences, 41 (2004): 613-628, Doi: 10.1016/j.ijrmms.2003.12.150.

[7] She, C. X. Deformation and stability of the right arch dam abutment of the Danjiang Hydro-Power project, China. International Journal of Rock Mechanics and Mining Sciences, 41 (2004): 792-797, Doi: 10.1016/j.ijrmms.2004.03.137.

[8] Yu, X., Zhou Y. F., and Peng S. Z. Stability analyses of dam abutments by 3D elasto-plastic finite-element method: a case study of Houhe gravity-arch dam in China. International journal of rock mechanics and mining sciences. 42.3 (2005): 415-430, Doi: 10.1016/j.jirmms.2005.01.001.

[9] Sohrabi Gilani M., Feldbacher R. and Zenz G., "Stability of dam abutment including seismic loading," in 10th Benchmark Workshop on Numerical Analysis of Dam, ICOLD, Paris, France, 2009.

[10] Zenz G., Goldgruber M. and Feldbacher R., "Seismic stability of a rock wedge in the abutment of an arch dam/Felskeilstabilität im Fundament einer Bogenstaumauer bei Erdbebenbelastung," Geomechanics and Tunnelling, 5 (2012): 186194.

[11] Takalloozadeh M. and Ghaemian M. "Shape optimization of concrete arch dams considering abutment stability". Scientia 
Iranica A, 21(4) (2014), 1297-1308.

[12] Mirzabozorg, H. Varmazyari, M. Hoseini, M. and Gharebaghi, S.,"A Comparative Study of Rock Wedge Stability of an Arch Dam Abutment Subjected to Static and Seismic Loading," Soil Mechanics and Foundation Engineering, 52 (2015): pp. 292-300, Doi: 10.1007/s11204-015-9344-6.

[13] Mahmoudi, P. P., Mirzabozorg, H., Varmazyari, M., \& Aghajanzadeh, S. M. "Effect of foundation nonlinearity on seismic response of an existing arch dam”. Civil engineering journal, 2(5) (2016), 197-207.

[14] Mostafaei, H. Sohrabi Gilani M., and Ghaemian, M., "Stability analysis of arch dam abutments due to seismic loading," Scientia Iranica A, 24 (2017): 467-475.

[15] Mostafaei, H. Sohrabi Gilani M., and Ghaemian, M., "The Effect of Grout Curtain Efficiency on Abutments Stability of an Arch Dam," 4th International Conference on Long-Term Behaviour and Enviromentally Friendly Rehabilitation Technologies of Dams, Tehran, Iran, 2017.

[16] Stucky, L. "Stability of dam abutment including seismic loading," presented at the Tenth Benchmark Workshop on Numerical Analysis of Dams, 2011. 